
3 Research Square
Preprints are preliminary reports that have not undergone peer review.
They should not be considered conclusive, used to inform clinical practice,
or referenced by the media as validated information.

\title{
Serum albumin predicts hyperuricemia in patients with idiopathic membranous nephropathy
}

Cuimei Wei

The First Affiliated Hospital of Shenzhen University

Tong LI

The First Affiliated Hospital of Shenzhen University

Xuan Xuan

The First Affiliated Hospital of Shenzhen University

Xiaohua Xiao ( $\sim 13622308340 @ 163 . c o m$ )

The First Affiliated Hospital of Shenzhen University

Junyi Li

The First Affiliated Hospital of Shenzhen University

\section{Research Article}

Keywords: serum albumin, hyperuricemia, uric acid ,cross-sectional study, idiopathic membranous nephropathy

Posted Date: March 2nd, 2021

DOI: https://doi.org/10.21203/rs.3.rs-199182/v1

License: () (1) This work is licensed under a Creative Commons Attribution 4.0 International License. Read Full License 


\section{Abstract}

Aim: The aim of the study was to examine the crosss-ectional association between serum albumin and hyperuricemia (HU).

Subjects and methods: $\mathrm{HU}$ was defined as uric acid $\geq 420 \mathrm{~mol} / \mathrm{L}$ for the male population and $\geq 357 \mathrm{~mol} / \mathrm{L}$ for the female population. We reviewed the files of 216 consecutive patients with Idiopathic membranous nephropathy treated at our hospital between 2010 and 2019 . The correlation of serum albumin with hyperuricemia and the association between serum uric acid levels and the clinical of Idiopathic membranous nephropathy were assessed by statistical analysis.A multivariable logistic analysis model was applied to test the association after adjusting for a number of potential confounding factors.

Results: Triglyceride and serum albumin were higher in group with hyperuricemia than in group without hyperuricemia( $(p=0.020, P<0.001$ respectively). As serum albumin rose for $1 \mathrm{~g} / \mathrm{L}$ the probability for hyperuricemia increased for $17 \%$ (adjusted II OR=1.17, 95\% $\mathrm{Cl}(1.02,1.35), P=0.0294)$. A unit increase in serum albumin was associated with increases of $6.64 \mathrm{umol} / \mathrm{L}$ in uric acid (adjusted II $\beta=6.64, P=0.0135$ ). Using Tertile 1 (T1) for reference, Tertile 3 (T3) group was positively associated with both hyperuricemia (adjusted II OR=44.21, 95\% Cl(12.76, 75.67), $P=0.0064$ ) and uric acid (adjusted II $\beta=98.64, P=0.0116$ ). The interaction test showed signifcant interactions between serum albumin and BMI when hyperuricemia or uric acid were used to determine the outcomes. The participants $\mathrm{BMI} \geq 25 \mathrm{~kg} / \mathrm{m}^{2}$ had a higher OR between serum albumin and hyperuricemia and had a higher $\beta$ between serum albumin and uric acid than $\mathrm{BM} \otimes 25 \mathrm{~kg} / \mathrm{m}^{2}$ (for hyperuricemia: $\mathrm{OR}=1.01 \mathrm{vs} 1.18$, $\mathrm{P}$ for interaction $=0.0056$; for uric acid: $\beta=0.96$ vs 6.23 , $\mathrm{P}$ for interaction $=0.0154$ ). The area under the ROC curve (AUC) was 0.7615 in the participants $\mathrm{BMI} \geq 25 \mathrm{~kg} / \mathrm{m}^{2}$. The sensitivity and specifcity of this point were $47.37 \%$ and $95.83 \%$,respectively.

Conclusion: Our study showed that serum albumin was positively associated with hyperuricemia and uric acid, especially in obese subjects.

\section{Introduction}

Membranous nephropathy $(\mathrm{MN})$ refers to a group of diseases characterized by the deposition of immune complexes in the epithelial cells of the glomerular basement membrane (GBM), accompanied by GBM thickening.Unexplained is called idiopathic membranous nephropathy (IMN). IMN is a common pathological types of nephrotic syndrome in adults ${ }^{[1]}$, and Accounted for 70-80\% of all membranous nephropathy (MN) patients. Recent studies have shown that the epidemiological characteristics of MN recent years significant changes have taken place, MN accounting primary glomerular diseases (PGD) of $23.4 \%$ ${ }^{[2]}$. The clinical features and prognosis of IMN are variable, ranging from spontaneous remission of nephrotic syndrome (up to $20-60 \%$ ) to a slow, progressive decline in glomerular filtration rate over several years. However, approximately $20 \%$ of IMN patients develop end-stage renal disease or die from related complications within 5 to 15 years. Recent epidemiological studies have shown that associated with hypertension and hyperuricemia IgAN patients with metabolic syndrome is an important risk factor for chronic kidney disease progression ${ }^{[3-6]}$. However, most controlled clinical studies have focused on determining the relationship between high blood pressure, hyperglycemia and kidney disease, few studies have examined the clinical and prognostic significance of serum uric acid in membranous nephropathy.It is reported that uric acid levels may predict renal function in individuals with normal renal function insufficiency of development and is associated with the onset of proteinuria and renal function in patients with type II diabetes mellitus ${ }^{[7]}$. Several observational studies examined the uric acid is an independent risk factor for chronic kidney disease (CKD) and progression ${ }^{[8-9]}$.We hypothesize that the serum uric acid is associated with initial worsening of IMN and plays a role in disease progression in IMN. Therefore,the goal of this study was to examine the association between serum albumin and hyperuricemia in a cohort of patients with Idiopathic membranous nephropathy.

\section{Materials And Methods}

Study Population. A total of 236 patients with biopsy proven membranous nephropathy (MN), treated at the First Affiliated Hospital of Shenzhen University from January 1, 2010 to December 12,2019 were evaluated for inclusion in this retrospective analysis, of whom 6 were excluded for atypical membranous nephropathy. Of the remaining 230 patients, patients with secondary MN $(n=14)$ were excluded. Finally a total of 216 patients ( 124 males: $57.41 \%$, mean age: $44.83 \pm 15.03$ years) with previously diagnosed IMN were included in the study. This study was reviewed and approved by the Ethics Committee of First Affiliated Hospital of Shenzhen University and was conducted in accordance with the guidelines of the Declaration of Helsinki. Written informed consent was obtained from each patient.

Clinical Parameters. Baseline data at the time of renal biopsy were obtained from medical records and included age, sex, the presence of hypertension (HTN). Laboratory data for serum creatinine,albumin, estimated glomerular filtration rate (eGFR), and the spot urine protein-to-creatinine ratio (UPCR) were obtained in the morning after admission under fasting conditions. The weight and height of each subject were measured,respectively, to calculate the body mass index (BMI). The smoking and alcohol drinking status were asked face to face. Blood pressure was measured by an electronic sphygmomanometer. Subjects with the systolic blood pressure $\geq 140 \mathrm{mmHg}$ or diastolic blood pressure $\geq 90 \mathrm{mmHg}$ or who were currently undergoing drug treatment for blood pressure control were regarded as hypertension patients. The estimated glomerular filtration rate (eGFR) was calculated using the Modification in Diet and Renal Disease $(\mathrm{MDRD})$ equation ${ }^{[10]}$. eGFR $\left[\mathrm{ml} / \mathrm{min} / 1.73 \mathrm{~m}^{2}\right]=175 \times$ [serum creatinine] $-1.234 \times$ [age]-0.179 $\times$ [femalex0.79]

Study Group Design. Patients were divided into groups with or without hyperuricemia depending on their serum uric acid levels at the time of renal biopsy.

Statistical Analysis. The $\chi^{2}$ test for categorical variables and the Kruskal-Wallis or Mann-Whitney test for continuous variables were used to compare univariate predictors of clinical outcomes between the two groups.Differences between groups using an independent t-test for continuous variables assessed, continuous variables are expressed as mean \pm standard deviation for categorical variables, frequencies and percentages.Logistic regression analysis was used to elucidate the association between hyperuricemia and other clinic parameters. The dependent variable was serum uric acid levels coded as 0 for IMN without hyperuricemia and coded as 1 for IMN with hyperuricemia. Interaction and stratifed analyses were conducted according to age ( $<45$ and $\geq 45 y e a r s)$, sex囚male and female『, smoking status (never smoked and smokers), drinking status (non-drinker and drinkers), histories of chronic diseases and some

Page $2 / 9$ 
clinicalharacteristics .Data were analyzed with the use of the statistical packages R (The R Foundation;http://www.r-project.org;version 3.4.3 2018-10-31) and Empower (R) (www.empowerstats.com; X\&Y Solutions Inc.).A p value $<0.05$ was considered to be statistically significant in all analyses.

\section{Results}

\section{Demographic and Clinical characteristics in the two serum uric acid groups}

Table 1 shows the biochemical parameters in idiopathic membranous nephropathy patients with or without hyperuricemia. Among the 216 confirmed cases of idiopathic membranous nephropathy, the prevalence of hyperuricemia was $46.2 \%$ (100/216). Most patients (116, 53.7\%) showed without hyperuricemia, and 101 patients (46.7\%) had nephrotic syndrome. When comparing patients with hyperuricemia versus those without hyperuricemia, we found no statistical significance in the following variables: age ,blood pressure, 24-hour urinary protein excretion,low density lipoprotein , HbA1C, Fasting blood glucose(GLU),and the alanine aminotransferase $\mathbb{A L T} \otimes(\mathrm{p}>0.05)$. There was significant difference in gender distribution $(P=0.018)$.The eGFR, total cholesterol, and high density lipoprotein were lower in group with hyperuricemia than in group without hyperuricemia ( $\mathrm{p} \otimes 0.05)$. In contrast, triglyceride and serum albumin were higher in group with hyperuricemia than in group without hyperuricemia $(p=0.020, P<0.001$ respectively).

Spearman's correlation analyses were performed to test the associations between serum uric acid and other clinical parameters. Serum uric acid was significantly negatively correlated with eGFR MDRD and high density lipoprotein and positively correlated with serum albumin,hemoglobin $\varangle \mathrm{HGB}$,triglyceride and body mass index (BMI) [Table2].

\section{Relationship between serum albumin and hyperuricemia.}

The relationship between serum albumin and hyperuricemia is presented in Table 3. Univariable and multivariable analyses were carried out to assess whether serum albumin is independently associated with hyperuricemia and uric acid after adjusting for likely confounders as age, sex, body mass index, smoking status, drinking status, AKI囚HBP囚HGB囚TG囚eGFR and 24-hour urinary protein. As serum albumin rose for $1 \mathrm{~g} / \mathrm{L}$ the probability for hyperuricemia increased for $17 \%$ (adjusted II OR=1.17, 95\% Cl $(1.02,1.35), P=0.0294)$. A unit increase in serum albumin was associated with increases of $6.64 \mathrm{umol} / \mathrm{L}$ in uric acid (adjusted II $\beta=6.64, P=0.0135$ ). With increasing serum albumin, there were signifcantly enhanced correlations of serum albumin with hyperuricemia and uric acid ( $p$ for the trend between quartiles $<0.05$ ). Using Tertile 1(T1) for reference, Tertile 3 (Q3) group was positively associated with both hyperuricemia (adjusted II OR=44.21, 95\% Cl $(12.76,75.67), P=0.0064)$ and uric acid (adjusted II $\beta=98.64, P=0.0116)$. These data are presented in Table3.

In order to accurately study the relationship between serum albumin and hyperuricemia,We need stratified analysis, test and covariate interactions screen out factors affecting their relationship. First, we analyze the relationship between hyperuricemia and all risk factors through stratified analysis (Table 4). Each continuous variable was divided into three groups according to its value. "Sex" group was divided into "male"and "female" groups on the basis of gender,et,al. The results indicated that there were no confounding factors between the layers. Conduct an interaction test to detect the influence of each stratified factor on the relationship between serum albumin and hyperuricemia or between serum albumin and uric acid. Pख0.05 means interaction exists between that factor and the relationship.The interaction test showed that when using hyperuricemia or uric acid to determine the results, there was no significant interaction between serum albumin and the above covariates, except for BMI (Table 4). Obese subjects are more important than the relationship between non-obese subjects. The participants $B M I \geq 25 \mathrm{~kg} / \mathrm{m}^{2}$ had a higher OR between serum albumin and hyperuricemia and had a higher $\beta$ between serum albumin and uric acid (for hyperuricemia: $\mathrm{OR}=1.01$ vs 1.18 , $\mathrm{P}$ for interaction $=0.0056$; for uric acid: $\beta=0.96$ vs $6.23, \mathrm{P}$ for interaction $=0.0154$ ).

In addition, smooth curve fiting was performed after the adjustment of the variables. We found a linear association of serum albumin and hyperuricemia. that is,serum albumin is positively correlated with hyperuricemia figure1.

In our study, ROC analysis was used to seek for the panel of parameters that might display the best specificity and sensitivity for discrimination of patients with hyperuricemia from those who did not have it. According to BMl,the patients were divided into two groups $\left(\left(<25 \mathrm{~kg} / \mathrm{m}^{2} \mathrm{vs} \geq 25 \mathrm{~kg} / \mathrm{m}^{2}\right)\right.$, the area under the ROC curve (AUC) was larger in obese subjects than in non-obese subjects. The area under the ROC curve (AUC) was 0.762 in the participants BMI $\geq 25 \mathrm{~kg} / \mathrm{m}^{2}$. The sensitivity and specifcity of this point were $47.37 \%$ and $95.83 \%$,respectively figure 2 .

\section{Discussion}

Chronic kidney disease(CKD) is a public health problem with many risk factors and its progression is hard to control. Thus it is more important to prevent the occurrence of this disease rather than to manage it.Hyperuricemia was reported to be a risk factor for CKD. Cirillo et al. previously found that serum uric acid plays an important role in the progression of CKD [11, 12]. In our cross sectional study, which was conducted to assess the clinical data of patients with different serum uric acid levels, we found there are significant differences in clinical and laboratory tests between patients with and without hyperuricemia groups. Hyperuricemia is often associated with chronic renal tubulointerstitial disease, which can lead to renal interstitial fibrosis at a later stage. Renal

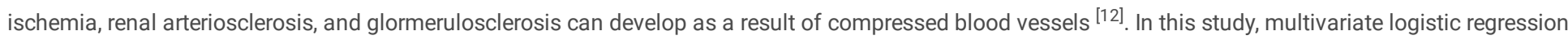
analysis showed that serum albumin kept independent prediction on hyperuricemia.

Uric acid is the metabolic end product of purine metabolism in humans ${ }^{[13]}$. In accordance with some reports, hyperuricemia induces endothelial dysfunction and low inflammation by inhibiting the production of nitric oxide and the production of reactive oxygen species. ${ }^{[14 \square 15 \square 16]}$. According to some researchs, there was a significant positive correlation between uric acid concentration and hs-CRP level, while serum albumin level was negatively correlated with hs-CRP. Serum albumin levels may be affected by the nutritional status as a nutritional marker囚high serum albumin level has been related to parameters indicative of over-nutrition, such as obesity and metabolic syndrome ${ }^{[17018019020]}$. Elevated serum albumin levels may reflect excessive nutritional status in the body, which may explain the relationship between elevated serum albumin levels and the risk of metabolic syndrome or hyperuricemia. ${ }^{\text {[21022] }}$. However, in the case of

Page $3 / 9$ 
chronic inflammation associated with hyperuricemia, albumin levels may be reduced by inflammation even in hypertrophic conditions, which may reduce the role of albumin as an indicator of overnutrition and serve as a marker for predicting incident metabolic syndrome ${ }^{\text {[21]. }}$

We found few studies on hyperuricemia incidence risk among idiopathic membranous nephropathy patients. To elucidate the impact of serum albumin on hyperuricemia in idiopathic membranous nephropathy patients, we estimated the association between serum albumin and the risk of hyperuricemia in both men and women. Our results suggest that elevated serum albumin is independently and positively associated with an increased risk of hyperuricemia in people,especially in the participants $\mathrm{BMI} \geq 25 \mathrm{~kg} / \mathrm{m}^{2}$. This cross-sectional study observed a signifcant association between the serum albumin level and the prevalence of hypeluricemia, independent of some major confounding factors. We find that triglyceride and serum albumin were higher in group with hyperuricemia than in group without hyperuricemia. Similarly serum uric acid was significantly positively correlated with serum albumin , triglyceride and body mass index (BMI).You-Bin Lee et,al. ${ }^{[21]}$ indicated that higher levels of albumin were associated with an increased risk of incident MetS only in individuals with lower uric acid whereas higher levels of uric acid were positively linked to risk of incident MetS regardless of albumin level. This study presented further evidence that hyperproteinemia plays a key role in the pathogenesis of $\mathrm{HU}$. The participants $\mathrm{BMI} \geq 25 \mathrm{~kg} / \mathrm{m}^{2}$ had a higher OR between serum albumin and hyperuricemia and had a higher $\beta$ between serum albumin and uric acid

The limitations of our study are cross-sectional design and small sample size. However, the present study has the strength. This is one of a few studies examined the association between serum albumin and the prevalence of hypeluricemia by regarding serum albumin as the primary exposure.In one crosssectional study indicated that the increased value of baseline serum albumin was positively associated with metabolic syndrome (MetS) prevalence or incidence $^{[23]}$.

\section{Conclusion}

In conclusion, as serum uric acid is a common and easily available measurement in clinical activity, it is a convenient and feasible way to identify those patients who are at high risk of developing end stage renal disease(ESRD)and with poor prognosis.we found that serum albumin levels are positively associated with hyperuricemia and uric acid especially patients with idiopathic membranous nephropathy,especially in obese subjects, which provide potential evidence that serum albumin may play an important role in regulating uric acid and hyperuricemia. Large prospective studies and independent replications are required to elucidate these issues.

\section{Declarations}

\section{Acknowledgement}

This research was supported by the First Affiliated Hospital of Shenzhen University.

\section{Author contributions}

Author contributions WCM, XX, LT and XH X contributed in the conception of the work, conducting the study, revising the draft, approval of the final version of the manuscript, and agreed for all aspects of the work. WCM and LJY contributed in the conception of the work, drafting and revising the draft. All authors read and approved the final version of the manuscript.

\section{Funding}

This study was supported in part by the basic research project and technology development projects of Shenzhen Municipal Science and Technology Innovation Council accounts JCY20180507184647636. All aspects of manuscript writing and revision were carried out by the coauthors.

\section{Availability of data and materials}

The datasets generated and/or analysed during the current study are not publicly available to protect the identification of the participants but are available from the corresponding author on reasonable request.

\section{Ethics approval and consent to participate}

This study was reviewed and approved by the Ethics Committee of First Affiliated Hospital of Shenzhen University and was conducted in accordance with the guidelines of the Declaration of Helsinki.All patients were informed that their anonymized personal data could be used for research. Written informed consent was obtained from each patient.

\section{Consent for publication}

Not applicable.

\section{Competing interests}

The authors declare that they have no competing interests.

\section{Author details}

${ }^{1}$ Department of Geriatrics, The First Affiliated Hospital of Shenzhen University, No. 3002 Sungang Road, Futian, Shenzhen 518035, Guangdong, China 
${ }^{2}$ Department of Nephrology, The First Affiliated Hospital of Shenzhen University, Shenzhen, Guangdong Province, 518000, China

${ }^{3}$ Department of Rheumatology, The First Affiliated Hospital of Shenzhen University, Shenzhen, Guangdong Province, 518000, China

${ }^{4}$ Shenzhen Second People's Hospital, Shenzhen, Guangdong Province, 518000, China

${ }^{5}$ Department of Applied Statistics, School of Applied Mathematics, Guangdong University of Technology, Guangzhou 510643, China

\section{References}

[1]Jan A.J.G.van den Brand,Hofstra,et al.Low-molecular-weight proteins as prognostic markers in idiopathic membranous nephropathy.Clin J Am Soc. Nephrol.2011;6(12):2846-2853.

[2]Xin Xu,Guobao Wang, Fan Fan Hou,et al.Long-Term Exposure to Air Pollution and Increased Risk of Membranous Nephropathy in China.J Am Soc Nephrol, 2016,27(12):3739-746.

[3]Chadban SJ, Briganti EM, Kerr PG, Dunstan DW, Welborn TA, Zimmet PZ, Atkins RC. Prevalence of kidney damage in Australian adults: The AusDiab kidney study. J Am Soc Nephrol. 2003;14 (Suppl 2): S131-S138.

[4] Romundstad S, Holmen J, Hallan H, Kvenild K,Krüger O, Midthjell K. Microalbuminuria, cardiovascular disease and risk factors in a nondiabetic/nonhypertensive population. The Nord-Trøndelag Health Study (HUNT, 1995-97), Norway. J Intern Med. $2002 ; 252$ (2): $164-172$.

[5] Iseki K, Kohagura K, Sakima A, Iseki C, Kinjo K, Ikemiya Y, Takishita S. Changes in the demographics and prevalence of chronic kidney disease in Okinawa, Japan (1993 to 2003). Hypertens Res. 2007; 30 (1): 55-62.

[6] Muntner P, He J, Astor BC, Folsom AR, Coresh J.Traditional and nontraditional risk factors predict coronary heart disease in chronic kidney disease: results from the atherosclerosis risk in communities study. J Am Soc Nephrol. 2005; 16 (2): 529-538.

[7] Zoppini G, Targher G, Chonchol M, Ortalda V,Abaterusso C, Pichiri I, Negri C, Bonora E. Serum uric acid levels and incident chronic kidney disease in patients with type 2 diabetes and preserved kidney function. Diabetes Care. 2012; 35 (1):99-104.

[8] Bellomo G, Venanzi S, Verdura C, Saronio P, Esposito A, Timio M. Association of uric acid with change in kidney function in healthy normotensive individuals. Am J Kidney Dis. 2010; 56 (2): 264-272.

[9] Rosolowsky ET, Ficociello LH, Maselli NJ, Niewczas MA, Binns AL, Roshan B, Warram JH,Krolewski AS. High-normal serum uric acid is associated with impaired glomerular filtration rate in nonproteinuric patients with type 1 diabetes. Clin J Am Soc Nephrol. 2008; 3 (3): 706-713.

[10]Levey AS, Eckardt KU, Tsukamoto Y, Levin A,Coresh J, Rossert J, De Zeeuw D, Hostetter TH,Lameire N, Eknoyan G. Definition and classification of chronic kidney disease: a position statement from Kidney Disease: Improving Global Outcomes(KDIGO). Kidney Int. 2005; 67 (6): $2089-2100$.

[11] Cirillo P, Sato W, Reungjui S, Heinig M, Gersch M, Sautin Y, Nakagawa T, Johnson RJ. Uric acid,the metabolic syndrome, and renal disease. J Am Soc Nephrol. 2006; 17 (12 Suppl 3): S165-S168.

[12] Barberi S, Menè P. Role of uric acid in hypertension and in the progression of chronic renal disease. G Ital Nefrol. 2006; $23(1)$ : 4-11.

[13]So A, Thorens B: Uric acid transport and disease. J Clin Invest 2010,120(6):1791-1799.

[14] Yu TY, Jee JH, Bae JC, Jin SM, Baek JH, Lee MK, Kim JH. Serum uric acid: a strong and independent predictor of metabolic syndrome afer adjusting for body composition. Metabolism. 2016;65(4):432-40.

[15]Khosla UM, Zharikov S, Finch JL, Nakagawa T,et,al. Hyperuricemia induces endothelial dysfunction. Kidney Int 2005;67(5):1739-42.

[16] Krajcoviechova A, Tremblay J, Wohlfahrt P, Bruthans J, Tahir MR, Hamet P, Cifkova R. The impact of blood pressure and visceral adiposity on the association of serum uric acid with albuminuria in adults without full metabolic syndrome. Am J Hypertens. 2016;29(12):1335-42.

[17] Ishizaka N, Ishizaka Y, Nagai R, Toda E, Hashimoto H, Yamakado M. Association between serum albumin, carotid atherosclerosis, and metabolic syndrome in Japanese individuals. Atherosclerosis. 2007;193(2):373-9.

[18] Kadono M, Hasegawa G, Shigeta M, Nakazawa A, Ueda M,Yamazaki M, Fukui M, Nakamura N. Serum albumin levels predict vascular dysfunction with paradoxical pathogenesis in healthy individuals. Atherosclerosis. 2010;209(1):266-70.

[19]Jin SM, Hong YJ, Jee JH, Bae JC, Hur KY, Lee MK, Kim JH.Change in serum albumin concentration is inversely and independently associated with risk of incident metabolic syndrome.Metabolism 2016;65(11):1629-35.

[20] Saito I, Yonemasu K, Inami F. Association of body mass index, body fat, and weight gain with inflammation markers among rural residents in Japan. Circ $J$ 2003;67(4):323-9. 
[21] You-Bin Lee, Ji Eun Jun, Seung-Eun Lee,et al. Utility of Serum Albumin for Predicting Incident Metabolic Syndrome according to Hyperuricemia. Diabetes Metab J. $2018 ; 42(6): 529-537$.

[22] Tuo Yang,Xiang Ding, Yi-lun Wang,et,al.Association between high sensitivity C reactive protein and hyperuricemia. Rheumatol Int.2016;36(4):561-566.

[23] Jin SM, Hong YJ, Jee JH, Bae JC, Hur KY, Lee MK, Kim JH.Change in serum albumin concentration is inversely and independently associated with risk of incident metabolic syndrome.Metabolism. 2016;65(11):1629-35.

\section{Tables}

Table 1: Demographic, clinical, and laboratory features of IMN patients with and without Hyperuricemia

\begin{tabular}{|c|c|c|c|}
\hline & IMN without Hyperuricemia & IMN with Hyperuricemia & $P$ value \\
\hline n (male/female) & $116 \square 58 / 58 \square$ & $100 \square 68 / 34 \square$ & 0.018 \\
\hline Agelyearl & $43.54 \pm 14.75$ & $46.33 \pm 15.29$ & 0.175 \\
\hline Alcohol $\llbracket n \square \% \square$ & $8(6.9 \%)$ & $8(8.00 \%)$ & 0.757 \\
\hline Smoke[n] \%ם & $12(10.34 \%)$ & $18(18 \%)$ & 0.105 \\
\hline Hypertension $\square n \square \% \square$ & $47(40.52 \%)$ & $53(53 \%)$ & 0.067 \\
\hline AKI $\square n \square \% \square$ & $4(3.45 \%)$ & $11(11 \%)$ & 0.029 \\
\hline $\mathrm{BMI} \mathrm{kg} / \mathrm{m}^{2} \square$ & $23.72 \pm 3.12$ & $25.11 \pm 4.45$ & 0.027 \\
\hline Systolic pressure $[\mathrm{mmHg} \square$ & $133.11 \pm 19.46$ & $135.49 \pm 20.94$ & 0.388 \\
\hline Diastolic pressure $(\mathrm{mmHg})$ & $80.96 \pm 11.68$ & $82.77 \pm 12.60$ & 0.274 \\
\hline 24-hour urinary protein $\llbracket \mathrm{mg} / \mathrm{d} \square$ & $3648.85(2253.25-5928.30)$ & $3267.45(1716.40-5464.80)$ & 0.197 \\
\hline HGB $(g / L)$ & $129.97 \pm 18.04$ & $134.23 \pm 20.27$ & 0.103 \\
\hline GLUTmmol/LD & $5.01 \pm 1.32$ & $4.84 \pm 0.82$ & 0.266 \\
\hline $\mathrm{HbA1}_{\mathrm{C}}{ }^{\square \square}$ & $5.86 \pm 1.84$ & $5.65 \pm 0.84$ & 0.425 \\
\hline Serum albumin $\llbracket g / L \square$ & $25.10 \pm 6.50$ & $28.30 \pm 7.51$ & $<0.001$ \\
\hline Uric acid $\square m m o l / L \square$ & $319.50 \pm 50.95$ & $469.58 \pm 74.39$ & $<0.001$ \\
\hline $\mathrm{eGFR} \rrbracket \mathrm{ml} / \min \square$ & $116.55 \pm 35.19$ & $102.31 \pm 30.43$ & 0.002 \\
\hline Total cholesterol $[\mathrm{mmol} / \mathrm{L} \square$ & $7.49 \pm 2.29$ & $6.96 \pm 2.14$ & 0.044 \\
\hline Triglyceride $\llbracket \mathrm{mmol} / \mathrm{L} \square$ & $1.67(1.19-2.69)$ & $2.11(1.50-3.05)$ & 0.020 \\
\hline High density lipoprotein $\square \mathrm{mmol} / \mathrm{L} \square$ & $1.53(1.19-1.82)$ & $1.23(1.06-1.54)$ & 0.006 \\
\hline Low density lipoprotein $\square \mathrm{mmol} / \mathrm{L} \square$ & $4.82 \pm 1.93$ & $4.53 \pm 1.87$ & 0.276 \\
\hline ALTIU/LD & $15.50(11.00-23.00)$ & $14.35(11.00-19.15)$ & 0.695 \\
\hline
\end{tabular}

Data are mean \pm SD or median (25th to 75 th percentile).

Abbreviations $₫ \mathrm{AKI}$,Acute kidney injury; BMI, body mass index; eGFR, estimated glomerular filtration rate; HGB, Hemoglobin; GLU, glucose; Glycated hemoglobin, $\mathrm{HbA}_{\mathrm{C}}$; ALT, alanine aminotransferase.

Table 2 Spearman's correlation analysis between serum uric acid and clinical parameters in patients with IMN 


\begin{tabular}{|c|c|c|}
\hline Predictors & Rho $(\rho)$ & $P$ value \\
\hline Agelyear & 0.0338 & 0.6215 \\
\hline Serum albumin $\square \mathrm{g} / \mathrm{L} \square$ & 0.2345 & 0.0005 \\
\hline eGFR(ml/min) & -0.2802 & 0.0000 \\
\hline 24-hour urinary protein $(\mathrm{g} / \mathrm{d})$ & -0.0868 & 0.2159 \\
\hline Triglyceride (mmol/L) & 0.2503 & 0.0002 \\
\hline Total cholesterol (mmol/L) & -0.1324 & 0.0525 \\
\hline High density lipoprotein $\backslash \mathrm{mmol} / \mathrm{L} \square$ & -0.1985 & 0.0035 \\
\hline Low density lipoprotein $\llbracket \mathrm{mmol} / \mathrm{L} \square$ & -0.0970 & 0.1565 \\
\hline ALTUU/LI & 0.0674 & 0.3300 \\
\hline 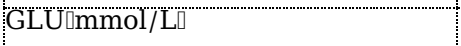 & -0.016 & 0.8101 \\
\hline HGB $\square / \mathrm{L} / \mathrm{L}$ & 0.2640 & 0.0001 \\
\hline Systolic pressure (mmHg) & 0.1039 & 0.1279 \\
\hline Diastolic pressure (mmHg) & 0.1579 & 0.0202 \\
\hline $\mathrm{BM} \square \mathrm{kg} / \mathrm{m} 2 \square$ & 0.3329 & 0.0000 \\
\hline
\end{tabular}

Table 3. Univariate and multivariate regression for effects of serum albumin on uric acid and hyperuricemia

\begin{tabular}{|c|c|c|c|c|c|c|c|c|c|}
\hline & \multicolumn{2}{|c|}{ hyperuricemia } & \multicolumn{6}{|c|}{ uric acid } & \multirow[b]{3}{*}{$\begin{array}{l}\mathrm{P} \\
\text { value }\end{array}$} \\
\hline & Crude & Adjust I & Adjust II & Crude & & Adjust I & & Adjust II & \\
\hline & OR,95\%CI & $\begin{array}{l}\mathrm{P} \\
\text { value }\end{array}$ & $\begin{array}{l}\mathrm{P} \\
\text { value }\end{array}$ & $\begin{array}{l}\mathrm{P} \\
\text { value }\end{array}$ & value & $\beta, 95 \% \mathrm{CI}$ & $\begin{array}{l}\mathrm{P} \\
\text { value }\end{array}$ & $\beta, 95 \% \mathrm{CI}$ & \\
\hline lbumin & $\begin{array}{l}1.07 \\
(1.03, \\
1.11)\end{array}$ & $\begin{array}{c}0.00131 .11(1.04 \\
1.17)\end{array}$ & $0.00061 .17(1.02,1.35)$ & $\begin{array}{r}0.02943 .21 \\
(1.43 \\
4.99)\end{array}$ & 0.000 & $53.91(1.87,5.94)$ & 0.0002 & $\begin{array}{l}26.64(1.66 \\
11.61)\end{array}$ & $0.01:$ \\
\hline \multicolumn{10}{|c|}{ rtiles $(\mathrm{g} / \mathrm{L})$} \\
\hline$(10.3-$ & 1.0 & 1.0 & 1.0 & 0 & - & 0 & - & 0 & - \\
\hline : (23.4- & $\begin{array}{l}1.42 \\
(0.73 \\
2.76)\end{array}$ & $\begin{array}{c}0.30871 .80(0.75 \\
4.32)\end{array}$ & $0.18750 .84(0.10,7.40)$ & $\begin{array}{c}0.87417 .34 \\
(-24.11 \\
38.80)\end{array}$ & 0.647 & $824.90(-8.81,58.61)$ & 0.1498 & $\begin{array}{l}8-10.46(-84.34 \\
63.41)\end{array}$ & 0.78 \\
\hline (29.7- & $\begin{array}{l}2.48 \\
(1.27 \\
4.85)\end{array}$ & $\begin{array}{l}0.00815 .11 \\
(2.02,12.93)\end{array}$ & $0.000626 .51(1.74,404.36)$ & $\begin{array}{r}0.018444 .21 \\
(12.76 \\
75.67)\end{array}$ & 0.006 & $467.23(32.23,102.24)$ & 0.0002 & $\begin{array}{l}298.64 \\
\quad(26.59,170.68)\end{array}$ & 0.011 \\
\hline nd & 0.0080 & 0.0006 & 0.0141 & 0.0064 & & 0.0002 & & 0.0079 & \\
\hline
\end{tabular}

Non-adjusted model adjust for: None

Adjusted I: age, sex, body mass index, smoking status, drinking status, hypertension,AKIロHBP

Adjusted II: age, sex, body mass index, smoking status, drinking status, hriglyceride, 24-hour urinary protein AKI0HGB; eGFR;

Table 4. Stratifed and interaction analysis for effects of serum albumin on uric acid and hyperuricemia 


\begin{tabular}{|c|c|c|c|c|c|}
\hline $\mathrm{im}$ albumin $\square \mathrm{g} / \mathrm{L} \square$ & hyperu & aricemia & & uric acid & \\
\hline group $\square \mathrm{N} \square$ & OR, 95\% CI & P Value & $\mathrm{P}$ intera & n OR, 95\% CI & $\mathrm{P}$ Value $\mathrm{P}$ interaction \\
\hline years old $\square 110 \square$ & $1.09(1.03,1.15)$ & 0.0025 & & $3.82(1.35,6.29)$ & 0.0031 \\
\hline & & & 0.3752 & & 0.3927 \\
\hline years oldø106 & $1.05(0.98,1.11)$ & 0.1542 & & $2.23(-0.38,4.84)$ & 0.0969 \\
\hline ıle『124] & $1.07(1.02,1.13)$ & 0.0114 & & $3.70(1.51,5.88)$ & 0.0012 \\
\hline male $₫ 92 \square$ & $1.10(1.02,1.18)$ & 0.0099 & 0.518 & $4.31(1.82,6.81)$ & 0.00110 .7218 \\
\hline king Habits & & & & & \\
\hline Oロ186ロ & $1.07(1.02,1.12)$ & 0.0034 & & $3.50(1.57,5.42)$ & 0.0005 \\
\hline »\$30! & $1.09(0.97,1.22)$ & 0.1620 & 0.7764 & $1.79(-2.47,6.05)$ & 0.41790 .4811 \\
\hline lking Habits & & & & & \\
\hline$) \square 200 \square$ & $1.07(1.02,1.11)$ & 0.0025 & & $3.32(1.43,5.20)$ & 0.00070 .7187 \\
\hline $\mathrm{s} \square 16 \square$ & $1.10(0.93,1.29)$ & 0.2608 & 0.7385 & $2.10(-2.81,7.01)$ & 0.4165 \\
\hline ertension & & & & & \\
\hline$) \square 116 \square$ & $1.06(1.00,1.12)$ & 0.0461 & & $1.48(-0.69,3.65)$ & 0.1851 \\
\hline $\mathrm{s} \square 100 \square$ & $1.09(1.02,1.16)$ & 0.0070 & 0.4507 & $5.43(2.60,8.25)$ & 0.00030 .0271 \\
\hline al insufficiency & & & & & \\
\hline $\mathrm{R} \geq 90 \mathrm{ml} / \mathrm{min} \square 153 \square$ & $1.09(1.04,1.15)$ & 0.0008 & & $3.24(1.18,5.31)$ & 0.0025 \\
\hline 'R $\square 90 \mathrm{ml} / \mathrm{min} \square 63 \square$ & $1.04(0.97,1.12)$ & 0.2557 & 0.3262 & $4.28(1.01,7.55)$ & 0.01270 .5904 \\
\hline hrotic syndrome & & & & & \\
\hline$\square 108 \square$ & $1.12(1.04,1.20)$ & 0.0015 & & $4.65(1.91,7.40)$ & 0.0012 \\
\hline $\mathrm{s} \square 101 \square$ & $1.08(0.99,1.17)$ & 0.0869 & 0.4846 & $4.59(0.75,8.43)$ & 0.02120 .9789 \\
\hline $\operatorname{HGB}(g / L)$ & & & & & \\
\hline $120 \square 58 \square$ & $1.07(0.98,1.18)$ & 0.1335 & & $2.45(-0.83,5.73)$ & 0.1492 \\
\hline$=120 \square 158 \square$ & $1.06(1.02,1.11)$ & 0.0090 & 0.8573 & $2.78(0.65,4.92)$ & 0.01150 .8802 \\
\hline lyceride $\llbracket \mathrm{mmol} / \mathrm{L} \square$ & & & & & \\
\hline$<1.7 \square 92 \square$ & $1.05(0.98,1.11)$ & 0.1553 & & $2.02(-0.20,4.24)$ & 0.0783 \\
\hline$>=1.7 \square 123 \square$ & $1.10(1.04,1.17)$ & 0.0011 & 0.2501 & $4.49(2.00,6.98)$ & 0.00060 .1615 \\
\hline il cholesterol $\llbracket \mathrm{mmol}$ & & & & & \\
\hline$<5.2 \square 40 \square$ & $1.11(0.96,1.29)$ & 0.1424 & & $4.84(-0.11,9.78)$ & 0.06260 .5858 \\
\hline$>=5.2 \square 175 \square$ & $1.06(1.01,1.11)$ & 0.0113 & 0.5395 & $3.08(0.86,5.31)$ & 0.0073 \\
\hline $\mathrm{BMI}(\mathrm{kg} / \mathrm{m} 2)$ & & & & & \\
\hline $\mathrm{BMI}<25(92)$ & $1.01(0.95,1.08)$ & 0.6488 & & $0.96(-1.62,3.53)$ & 0.4688 \\
\hline $\mathrm{BMI} \geq 25(62)$ & $1.18(1.07,1.31)$ & 0.0011 & 0.0056 & $6.23(2.64,9.82)$ & 0.00120 .0154 \\
\hline
\end{tabular}

\section{Figures}






Figure 1

Smooth curve ftting of serum albumin and hyperuricemia Adjustment variables: age, sex, body mass index, smoking status, drinking status, hypertension ,AKI, HGB; TG; eGFR; 24-hour urinary protein

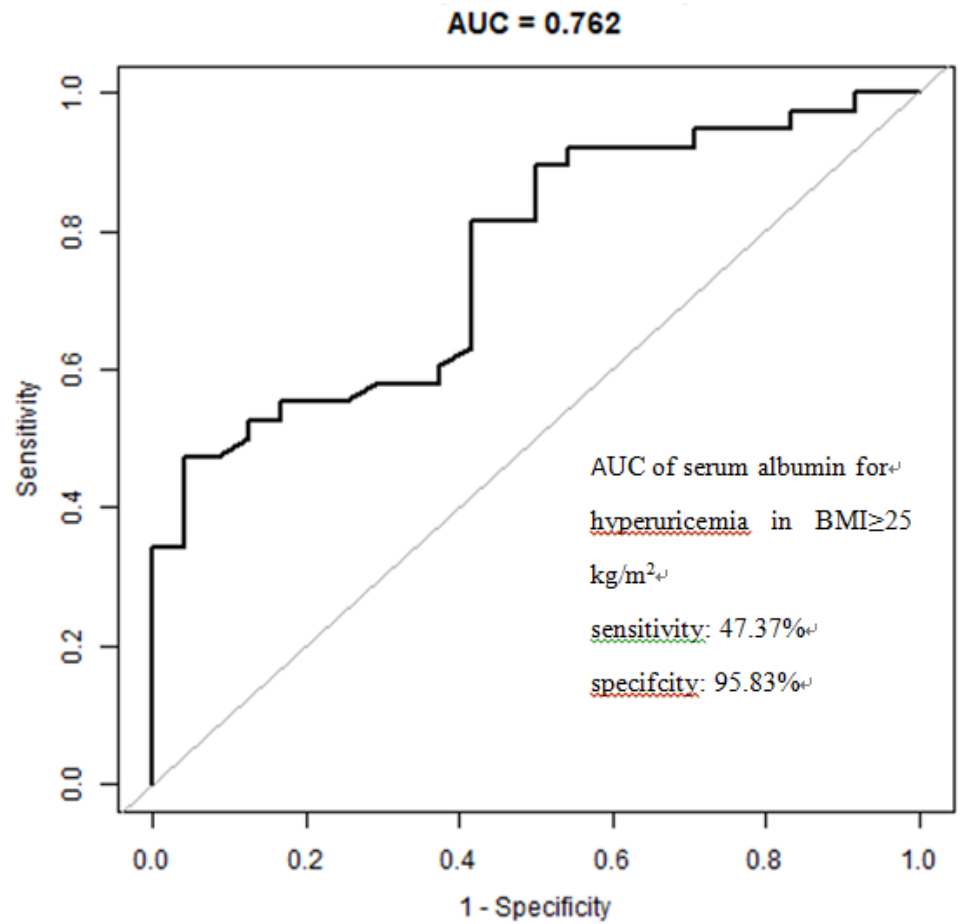

\section{Figure 2}

ROC curve of the relationship between serum albumin and hyperuricemia in $\mathrm{BMl} \geq 25 \mathrm{~kg} / \mathrm{m} 2$ 